\title{
Research Square \\ Transmission Design of Bevel Gear with Arbitrary Crossed Axes and Its Application in the Knotter
}

Jianjun Yin ( $\square$ yinjianjun@ujs.edu.cn )

Jiangsu University https://orcid.org/0000-0002-7068-3092

Han Wu

Jiangsu University

Zheng Ji

Jiangsu University

Maile Zhou

Jiangsu University

Ruipeng Guo

Jiangsu University

Original Article

Keywords: gear transmission, bevel gear with crossed axes, tooth profile calculation, knotter

Posted Date: September 27th, 2021

DOl: https://doi.org/10.21203/rs.3.rs-924003/v1

License: (9) This work is licensed under a Creative Commons Attribution 4.0 International License.

Read Full License 


\title{
Transmission Design of Bevel Gear with Arbitrary Crossed Axes and Its Application
}

\section{in the Knotter}

\author{
Jianjun Yin*, Han Wu, Zheng Ji, Maile Zhou and Ruipeng Guo
}

\begin{abstract}
The bevel gear transmission with crossed axes is widely used, but there are the difficulty of tooth profile calculation and modeling in the design and manufacturing process. This paper analyzes firstly the parameter solving equation of the bevel gear pair with arbitrary crossed axes. Based on the meshing principle of the bevel gear pair and numerical analysis method, the meshing equations of the bevel gear pair with crossed axes are derived, which provide the calculation models for the design of spatial bevel gear tooth surface. Taking the bevel gear pair with crossed axes in two kinds of the knotter as two design examples, the geometric parameters of the bevel gear pair in the knotter are solved, and the mathematical models of the tooth surface are programmed and calculated by using MATLAB. Through the graphic display of the tooth surface point set under MATLAB software and the 3D modeling function of Pro/Engineering software, the accurate 3D models of the bevel gear tooth surface are established. The meshing transmission simulations of the established bevel gear pair are respectively carried out by using ADAMS, and their physical prototype and transmission tests are also implemented. The test results showed that the transmission of the designed bevel gear pair is accurate and stable, which proves the correctness of the derived calculation model of the tooth surface of the bevel gear with crossed axes.
\end{abstract}

Key words: gear transmission; bevel gear with crossed axes; tooth profile calculation; knotter

\section{Introduction}

It is generally known that gear transmission has an extremely important role in the equipment manufacturing of industry and agriculture. With the continuous progress of gear technology research, the requirements of higher performance are also directly put forward, such as higher transmission efficiency, transmission accuracy and reliability [1]. As an important form of gear transmission, the bevel gear with crossed axes is widely used in industrial and agricultural fields. Its design theory and modeling method have always been a hot topic in the field of gear transmission [2]. The research on the parameter calculation model and accurate three-dimensional modeling of the bevel gear with arbitrary crossed axes has great significance to improve of the bevel gear transmission.

At present, the researches of gear transmission mainly focus on gear life assessment techniques [3-6], theoretical research on gear reinforcement [7-10], computer-aided design method of gear [11-13] and gear fault detection research [14-18]. There are few theoretical studies on gear mathematical models based on numerical analysis methods. The relationship among tooth pressure, helix angle and tool system parameter was established according to the accurate geometry of tool system in hyperbolic gear forming, and a new parameterization method of gear tooth surface was introduced [19]. Based on the mathematical modeling method of helical bevel gear, the deviation between the actual tooth surface shape and the theoretical tooth surface shape was expressed by polynomial expression, and a method of

*Correspondence: yinjianjun@ujs.edu.cn

School of Agricultural Engineering, Jiangsu University, Zhenjiang 212013, China

Full list of author information is available at the end of the article remanufacturing the existing helical bevel gear pinion by using NC machining center was proposed [20]. The concept of auxiliary surface of Camus is extended to the design case of involute gear with crossed axes [21]. The geometric characteristics of tooth profile of crossed shaft gear set are studied by using pressure angle function, meshing equation and continuity condition constraints [22]. By studying the surface modification method of helical bevel gear, an accurate computer design method of spur bevel gear and helical bevel gear is proposed [23]. According to the requirements of helical gear installation position, a pre size method of helical gear transmission data based on application requirements is proposed [24]. It can be seen that research on gear transmission design is mostly concentrated in the field of cylindrical gear, and there is relatively little knowledge about bevel gear transmission design. The derivation of meshing equation of bevel gear tooth surface based on bevel gear meshing principle and accurate modeling of bevel gear pair are a challenge faced by the machinery industry [25].

This study derives the mathematical model of tooth profile of bevel gear with arbitrary crossed axes and proposes an accurate 3D modeling method of tooth profile of bevel gear. The organization of this paper is as follows: Section 2 presents a brief summary on parameter calculation model of bevel gear pair with crossed axes; The establishment of mathematical model for tooth surface of bevel gear pair with crossed axes is introduced in Section 3; Section 4 gives the two calculation and design examples of bevel gear pair in the knotter; and Section 5 has concluding remarks.

\section{Parameter Calculation Model of Bevel Gear Pair with Crossed Axes}

The layout form of the bevel gear pair studied in this paper is shown in Figure 1 [26, 27]. The axis of bevel gear 2 is located at the rear and fixed, the big ends of the two bevel 
gears are on the opposite side, and the vertex of the cone of bevel gear 1 points to the right side of the axis of gear 2 .

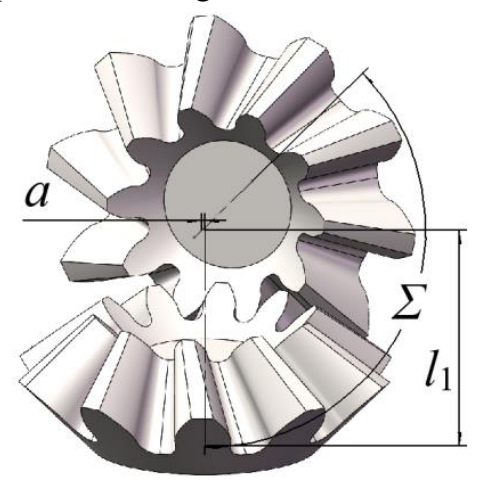

Figure1 Layout form of the bevel gear pair

The installation parameter method is used to solve the geometric parameters of the bevel gear pair [28]. The known parameters include gear normal modulus $m_{\mathrm{n}}$, normal pressure angle $\alpha_{\mathrm{n}}$, helical angle $\beta_{1}$, number of teeth $z_{1}$ and $z_{2}$, pitch cone angle $\delta_{1}$, crossed axis angle $\Sigma$, wheel base $a$, and installation distance of gear $1 l_{1}$. Firstly, the tooth profile angle coefficient of the bevel gear $\xi_{t 1}$ is preset, and the pitch radius $r_{1}^{\prime}$ of the bevel gear is calculated by Eq. (1).

$$
r_{1}^{\prime}=\frac{r_{1}}{\xi_{t 1}}=\frac{m_{n} z_{1}}{2 \cos \beta_{1} \xi_{t 1}}
$$

The indexing circle pressure angle $\alpha_{\mathrm{t} 1 \mathrm{~L}}$ and $\alpha_{\mathrm{t} 1 \mathrm{R}}$ of the left and right end face tooth profile of the bevel gear 1, and the pitch pressure angle $\alpha_{\mathrm{t} 1 \mathrm{~L}}^{\prime}$ and $\alpha_{\mathrm{t} 1 \mathrm{R}}^{\prime}$ of the left and right end face tooth profile of the bevel gear 1 are calculated by Eq. (2) and Eq. (3).

$$
\begin{aligned}
& \left\{\begin{array}{l}
\tan \alpha_{\mathrm{t} 1 \mathrm{~L}}=\frac{\tan \alpha_{n} \cos \delta_{1}}{\cos \beta_{1}}-\sin \delta_{1} \tan \beta_{1} \\
\tan \alpha_{\mathrm{t} 1 \mathrm{R}}=\frac{\tan \alpha_{n} \cos \delta_{1}}{\cos \beta_{1}}+\sin \delta_{1} \tan \beta_{1}
\end{array}\right. \\
& \left\{\begin{array}{l}
\cos \alpha_{\mathrm{t} 1 \mathrm{~L}}^{\prime}=\xi_{t 1} \cos \alpha_{\mathrm{t} 1 \mathrm{~L}} \\
\cos \alpha_{\mathrm{t} 1 \mathrm{R}}^{\prime}=\xi_{t 1} \cos \alpha_{\mathrm{t} 1 \mathrm{R}}
\end{array}\right.
\end{aligned}
$$

The intersection angle $\delta_{1}^{\prime}$ between the imaginary common gear rack indexing plane and the axis of bevel gear 1 can be calculated by Eq. (4).

$$
\left\{\begin{array}{l}
\delta_{1}^{\prime}=\arctan \left(\xi_{t 1} \frac{\tan \alpha_{\mathrm{t} 1 \mathrm{R}}^{\prime}-\tan \alpha_{\mathrm{t} 1 \mathrm{~L}}^{\prime}}{2 \cos \delta_{1} \tan \beta_{1}}\right)\left(\beta_{1} \neq 0\right) \\
\delta_{1}^{\prime}=\arctan \frac{\tan \alpha_{\mathrm{n}} \sin \delta_{1}}{\xi_{t 1} \tan \alpha_{\mathrm{t} 1 \mathrm{R}(\mathrm{L})}^{\prime}}\left(\beta_{1}=0\right)
\end{array}\right.
$$

To the imaginary common gear rack, the normal pressure angle $\alpha_{n}^{\prime}$, the inclination angle $\beta_{1}^{\prime}$ of the tooth trace of the indexing plane and the normal modulus $m_{n}^{\prime}$ can be calculated by Eq. (5) - (7).

$$
\begin{gathered}
\alpha_{\mathrm{n}}^{\prime}=\arcsin \left(\sin \alpha_{n} \frac{\sin \delta_{1}}{\sin \delta_{1}^{\prime}}\right) \\
\beta_{1}^{\prime}=\arctan \left(\frac{\cos \delta_{1} \tan \beta_{1}}{\xi_{t 1} \cos \delta_{1}^{\prime}}\right) \\
m_{\mathrm{n}}^{\prime}=\frac{m_{n} \cos \beta_{1}^{\prime}}{\xi_{t 1} \cos \beta_{1}}
\end{gathered}
$$

Then, wheel base $a$, and installation distance of gear $1 l_{1}$ can be expressed as follows:

$$
\begin{gathered}
l_{1}=\frac{\left(r_{1}^{\prime} \cos \delta_{2}^{\prime}+r_{2}^{\prime} \cos \delta_{1}^{\prime}\right)\left(\sin \delta_{1}^{\prime}+\sin \delta_{2}^{\prime} \cos \sum\right)}{\cos \delta_{1}^{\prime} \cos \delta_{2}^{\prime} \sin ^{2} \sum}-r_{1}^{\prime} \tan \delta_{1}^{\prime} \\
a=\frac{\left(r_{1}^{\prime} \cos \delta_{2}^{\prime}+r_{2}^{\prime} \cos \delta_{1}^{\prime}\right) \sin \varepsilon^{\prime}}{\sin \sum}
\end{gathered}
$$

The sharp angle $\varepsilon$ ' between two conical buses of bevel gears 1 and 2 is

$$
\varepsilon^{\prime}=\arccos \left(\frac{\cos \sum+\sin \delta_{1}^{\prime} \sin \delta_{2}^{\prime}}{\cos \delta_{1}^{\prime} \cos \delta_{2}^{\prime}}\right)
$$

So, the included angle $\delta_{2}^{\prime}$ between the axis of bevel gear 2 and the imaginary common gear rack indexing plane may be calculated by simultaneous Eq. (8) - (10), and $\delta_{1}^{\prime}$ is substituted by a negative value.

Next, the inclination angle $\beta_{2}^{\prime}$ of the imaginary common gear rack tooth trace, the pitch cone angle $\delta_{2}$ of gear 2 , the tooth profile angle coefficient $\xi_{t 2}$ and helix angle $\beta_{2}$ are obtained by Eq. (11) - (13).

$$
\begin{gathered}
\beta_{2}^{\prime}=-\varepsilon^{\prime}-\beta_{1}^{\prime} \\
\delta_{2}=\arcsin \left(\frac{\sin \delta_{2}^{\prime} \sin \alpha_{n}^{\prime}}{\sin \alpha_{n}}\right) \\
\tan \beta_{2}^{\prime}=\frac{\cos \delta_{2} \tan \beta_{2}}{\xi_{t 2} \cos \delta_{2}^{\prime}} \\
m_{n}^{\prime}=\frac{m_{n} \cos \beta_{2}^{\prime}}{\xi_{t 2} \cos \beta_{2}}
\end{gathered}
$$

Thus, the pitch radius of bevel gear 2 may be expressed as follows:

$$
\left\{\begin{array}{l}
r_{2}^{\prime}=\frac{z_{2} m_{n}}{2 \cos \beta_{2} \xi_{t 2}} \\
r_{2}^{\prime \prime}=\frac{z_{2} m_{n}^{\prime}}{2 \cos \beta_{2}^{\prime}}
\end{array}\right.
$$

If a proper preset tooth profile angle coefficient $\xi_{t l}$ of bevel gear 1 is selected and $r_{2}=r_{2}{ }_{2}$ is satisfied finally, the above all parameters of the designed bevel gear pair will be determined.

\section{Establishment of Mathematical Model for Tooth Surface of Bevel Gear Pair with Crossed Axes}

\subsection{Derivation of Mathematical Model of Imaginary Gear Rack Tooth Surface}

The normal section of imaginary gear rack is shown as Figure 2.

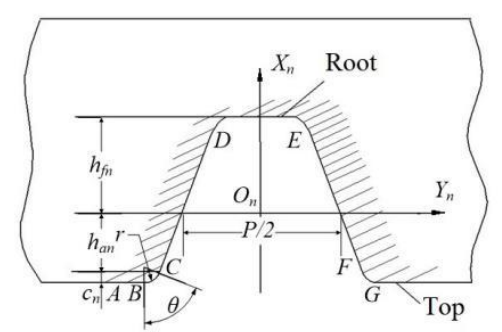

Figure 2. The normal section of imaginary gear rack

Assumed that the straight segments $C D$ and $E F$ of the imaginary common gear rack envelop the involute tooth face 
of bevel gear, the geometric parameter equation of the line segments can be expressed as follows:

$$
f_{n}^{1}(t)=\left\{\begin{array}{l}
x_{n}^{1}=t \cos \alpha_{n}-h_{a n}^{*} m_{n} \\
y_{n}^{1}= \pm\left(t \sin \alpha_{n}-\frac{p}{4}-h_{a n}^{*} m_{n} \tan \alpha_{n}\right) \\
z_{n}^{1}=0
\end{array}\right.
$$

where $f_{n}^{1}(t)$ is the coordinate value of the point on the skew straight tooth profile of the gear rack in the coordinate system $S_{n}$ shown in Figure 3. $t$ is a parametric variable, and represents the distance from any point on the oblique line to point $C$ or point $F$, and satisfies this inequality constraint $0 \leq t \leq 2 h_{a n}^{*} m_{n}$ $/ \cos \alpha_{n} . p$ is gear pitch, and $p=\pi m$.

Similarly, the arc segments $B C$ and $F G$ envelop the transition curve between the tooth root and the involute tooth surface, the geometric parameter equation of the arc segments can be expressedas follows:

$$
f_{n}^{2}(\theta)=\left\{\begin{array}{l}
x_{n}^{2}=r-\left(h_{a n}^{*}+c_{n}^{*}\right) m+r \cos \theta \\
y_{n}^{2}= \pm\left(-r \cos \alpha_{n}-\frac{p}{4}-h_{a n}^{*} m_{n} \tan \alpha_{n}+r \sin \theta\right) \\
z_{n}^{2}=0
\end{array}\right.
$$

where $f_{n}^{2}(\theta)$ is the coordinate value of the point on the transition arc of the gear rack in the coordinate system $S_{n}$ shown in Figure 3. $\theta$ is a parameter variable, represents the angle of the transition arc, and ranges from $\frac{\pi}{2}+\alpha_{n}$ to $\pi . r$ is fillet radius of tooth top, and $r=\frac{c_{n}^{*} m_{n}}{1-\sin \alpha_{n}}$.

As shown in Figure 3, the imaginary common gear rack indexing plane is tangent to the pitch cone of bevel gear, and the pitch plane is tangent to the indexing cylinder of bevel gear. $S_{n}$ is the coordinate system of the imaginary common gear rack normal section. $S_{p}$ is the coordinate system of the imaginary common gear rack indexing plane. $\beta$ is the inclination angle of tooth trace on the indexing plane when the gear meshes with the imaginary common gear rack. $S_{c}$ is the coordinate system of the pitch plane of the imaginary common gear rack, which is tangent to the indexing cylinder of bevel gear. $S_{0}$ is the coordinate system of gear, the coordinate system $S_{0}$ changes to the coordinate system $S_{1}$ when the gear rotates at an angle of $\varphi_{1} . \delta$ represents the angle between the imaginary common gear rack indexing plane and the axis of the gear.

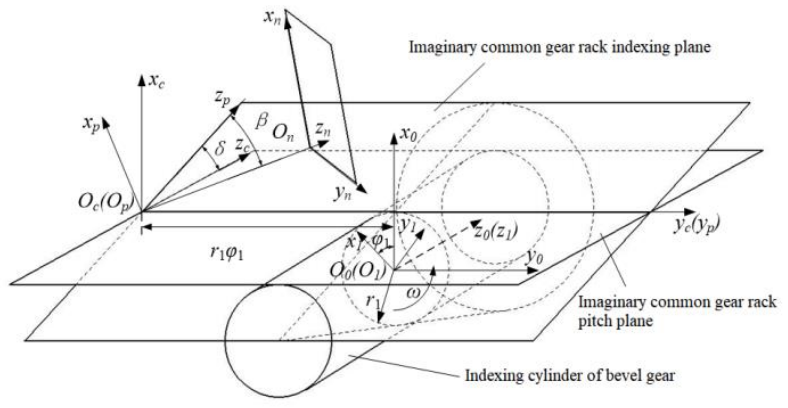

Figure 3. Definition of the coordinate systems and relative position relationship between gear and gear rack

For the normal section plane equation of the gear rack, the transformation relationship from the coordinate system $S_{n}$ to the coordinate system $S_{c}$ can be expressed in Eq. (17):

$$
\left(\begin{array}{c}
x_{c} \\
y_{c} \\
z_{c} \\
t_{c}
\end{array}\right)=M_{c n}\left(\begin{array}{c}
x_{n} \\
y_{n} \\
z_{n} \\
t_{n}
\end{array}\right)
$$

where $M_{c n}$ is the transition matrix of gear rack normal section equation from the coordinate system $S_{n}$ to $S_{c}$, and $M_{c n}=\left[\begin{array}{cccc}\cos \delta & -\sin \delta \sin \beta & \sin \delta \cos \beta & k \sin \delta \cos \beta \\ 0 & \cos \beta & \sin \beta & k \sin \beta \\ -\sin \delta & -\cos \delta \sin \beta & \cos \delta \cos \beta & k \cos \delta \cos \beta \\ 0 & 0 & 0 & 1\end{array}\right]$.

By substituting Eq. (15) into Eq. (17), Eq. (18) can be obtained as follows:

$$
f_{c}^{1}(k, t)=M_{c n} \cdot f_{n}^{1}(t)=\left\{\begin{array}{c}
x_{c}^{1}=k \sin \delta \cos \beta+\cos \delta\left(t \cos \alpha_{n}-h_{a n}^{*} m_{n}\right) \\
\mu \sin \delta \sin \beta\left(t \sin \alpha_{n}-\frac{p}{4}-h_{a n}^{*} m_{n} \tan \alpha_{n}\right) \\
y_{c}^{1}=k \sin \beta \pm \cos \beta\left(t \sin \alpha_{n}-\frac{p}{4}-h_{a n}^{*} m_{n} \tan \alpha_{n}\right) \\
z_{c}^{1}=k \cos \delta \cos \beta-\sin \delta\left(t \cos \alpha_{n}-h_{a n}^{*} m_{n}\right) \\
\mu \cos \delta \sin \beta\left(t \sin \alpha_{n}-\frac{p}{4}-h_{a n}^{*} m_{n} \tan \alpha_{n}\right)
\end{array}\right.
$$

where $f_{c}^{t}(k, t)$ represents the equation of the tooth surface formed by the normal section straight segment of the imaginary common gear rack in the coordinate system $S_{c} ; k$ represents the tooth width, and $t$ represents a parameter of the tooth depth; and superscript 1 denotes a surface generated by a straight segment of the imaginary common gear rack.

By substituting Eq. (16) into Eq. (17), Eq. (19) can be obtained as follows:

$$
f_{c}^{2}(k, \theta)=M_{c n} \cdot f_{n}^{2}(\theta)=\left\{\begin{array}{c}
x_{c}^{2}=k \sin \delta \cos \beta+\cos \delta\left(r-\left(h_{a n}^{*}+c_{n}^{*}\right) m_{n}+r \cos \theta\right) \\
\mu \sin \delta \sin \beta\left(-r \cos \alpha_{n}-\frac{p}{4}-h_{a n}^{*} m_{n} \tan \alpha_{n}+r \sin \theta\right) \\
y_{c}^{2}=k \sin \beta \pm \cos \beta\left(-r \cos \alpha_{n}-\frac{p}{4}-h_{a n}^{*} m_{n} \tan \alpha_{n}+r \sin \theta\right) \\
z_{c}^{2}=k \cos \delta \cos \beta-\sin \delta\left(r-\left(h_{a n}^{*}+c_{n}^{*}\right) m+r \cos \theta\right) \\
\mu \cos \delta \sin \beta\left(-r \cos \alpha_{n}-\frac{p}{4}-h_{a n}^{*} m_{n} \tan \alpha_{n}+r \sin \theta\right)
\end{array}\right.
$$

where $f_{c}^{2}(k, \theta)$ represents the equation of the tooth surface formed by the transition curve section equation of the imaginary common gear rack normal section in the coordinate system $S_{c} ; k$ represents tooth width, and $\theta$ represents a parameter of transition radian; and superscript 2 represents the surface generated by the transition curve segment.

The coordinate transformation relationship from the coordinate system $S_{c}$ to the gear coordinate system $S_{1}$ is given in Eq. (20):

$$
\left(\begin{array}{l}
x_{1} \\
y_{1} \\
z_{1} \\
t_{1}
\end{array}\right)=M_{1 c}\left(\begin{array}{c}
x_{c} \\
y_{c} \\
z_{c} \\
t_{c}
\end{array}\right)
$$

where $M_{1 c}$ is the transformation matrix of the equation from the coordinate system $S_{c}$ to $S_{1}$, and expressed as

$$
M_{1 c}=\left[\begin{array}{cccc}
\cos \varphi_{1} & -\sin \varphi_{1} & 0 & r_{1}\left(\cos \varphi_{1}+\varphi_{1} \sin \varphi_{1}\right) \\
\sin \varphi_{1} & \cos \varphi_{1} & 0 & r_{1}\left(\sin \varphi_{1}-\varphi_{1} \cos \varphi_{1}\right) \\
0 & 0 & 1 & 0 \\
0 & 0 & 0 & 1
\end{array}\right] .
$$

By substituting Eq. (18) into Eq. (20), the expression of the plane equation formed by the straight segment of the imaginary common gear rack in the coordinate system $S_{1}$ may be derived and shown in Eq. (21). Accordingly, by 
substituting Eq. (19) into Eq. (20), the expression of the may be derived and shown in Eq. (22). surface equation formed by the transition curve segment of the imaginary common gear rack in the coordinate system $S_{1}$

$$
\begin{aligned}
& \left\{\begin{array}{c}
x_{1}^{1}=\cos \varphi_{1}\left(k \sin \delta \cos \beta+\cos \delta\left(t \cos \alpha_{n}-h_{a n}^{*} m_{n}\right)\right. \\
\left.\mu \sin \delta \sin \beta\left(t \sin \alpha_{n}-\frac{p}{4}-h^{*} m_{n} \tan \alpha_{n}\right)\right)
\end{array}\right. \\
& \left.\mu \sin \delta \sin \beta\left(t \sin \alpha_{n}-\frac{p}{4}-h_{a n}^{*} m_{n} \tan \alpha_{n}\right)\right) \\
& -\sin \varphi_{1}\left(k \sin \beta \pm \cos \beta\left(t \sin \alpha_{n}-\frac{p}{4}-h_{a n}^{*} m_{n} \tan \alpha_{n}\right)\right) \\
& +r_{1}\left(\cos \varphi_{1}+\varphi_{1} \sin \varphi_{1}\right) \\
& y_{1}^{1}=\sin \varphi_{1}\left(k \sin \delta \cos \beta+\cos \delta\left(t \cos \alpha_{n}-h_{a n}^{*} m_{n}\right)\right. \\
& \left.\mu \sin \delta \sin \beta\left(t \sin \alpha_{n}-\frac{p}{4}-h_{a n}^{*} m_{n} \tan \alpha_{n}\right)\right) \\
& +\cos \varphi_{1}\left(k \sin \beta \pm \cos \beta\left(t \sin \alpha_{n}-\frac{p}{4}-h_{a n}^{*} m_{n} \tan \alpha_{n}\right)\right) \\
& +r_{1}\left(\sin \varphi_{1}-\varphi_{1} \cos \varphi_{1}\right) \\
& z_{1}^{1}=k \cos \delta \cos \beta-\sin \delta\left(t \cos \alpha_{n}-h_{a n}^{*} m_{n}\right) \\
& \mu \cos \delta \sin \beta\left(t \sin \alpha_{n}-\frac{p}{4}-h_{a n}^{*} m_{n} \tan \alpha_{n}\right) \\
& f_{1}^{2}\left(\varphi_{1}, k, \theta\right)=M_{1 c} \cdot f_{c}^{2}(k, \theta)=\left\{\begin{aligned}
x_{1}^{2}= & \cos \varphi_{1}\left(k \sin \delta \cos \beta+\cos \delta\left(r-\left(h_{a n}^{*}+c_{n}^{*}\right) m_{\mathrm{n}}+r \cos \theta\right)\right. \\
& \left.\mu \sin \delta \sin \beta\left(-r \cos \alpha_{n}-\frac{p}{4}-h_{a n}^{*} m_{n} \tan \alpha_{n}+r \sin \theta\right)\right) \\
& -\sin \varphi_{1}\left(k \sin \beta \pm \cos \beta\left(-r \cos \alpha_{n}-\frac{p}{4}-h_{a n}^{*} m_{n} \tan \alpha_{n}+r \sin \theta\right)\right) \\
& +r_{1}\left(\cos \varphi_{1}+\varphi_{1} \sin \varphi_{1}\right) \\
y_{1}^{2}= & \sin \varphi_{1}\left(k \sin \delta \cos \beta+\cos \delta\left(r-\left(h_{a n}^{*}+c_{n}^{*}\right) m+r \cos \theta\right)\right. \\
& \left.\mu \sin \delta \sin \beta\left(-r \cos \alpha_{n}-\frac{p}{4}-h_{a n}^{*} m_{n} \tan \alpha_{n}+r \sin \theta\right)\right) \\
& +\cos \varphi_{1}\left(k \sin \beta \pm \cos \beta\left(-r \cos \alpha_{n}-\frac{p}{4}-h_{a n}^{*} m_{n} \tan \alpha_{n}+r \sin \theta\right)\right) \\
& +r_{1}\left(\sin \varphi_{1}-\varphi_{1} \cos \varphi_{1}\right) \\
z_{1}^{2}= & k \cos \delta \cos \beta-\sin \delta\left(r-\left(h_{a n}^{*}+c_{n}^{*}\right) m+r \cos \theta\right) \mu \cos \delta \sin \beta\left(-r \cos \alpha_{n}-\frac{p}{4}\right. \\
& \left.-h_{a n}^{*} m_{n} \tan \alpha_{n}+r \sin (\theta)\right)
\end{aligned}\right.
\end{aligned}
$$

\subsection{Derivation of Bevel Gear Meshing Equation and Tooth} Surface Equation

According to the basic theorem of tooth profile meshing [29], assuming that the meshing points of gear and gear rack are represented by $D\left(x_{c}, y_{c}, z_{c}\right)$ in the coordinate system $S_{c}$, then they have a common tangent and normal at meshing point $D$, as shown in Figure 4 .

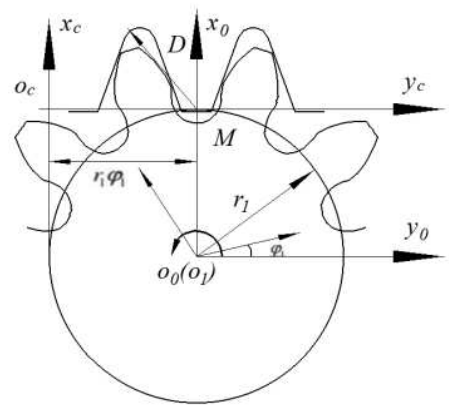

Fig.4. Meshing relationship between gear and gear rack

The relative motion velocity $\overrightarrow{v^{(12)}}$ at the tangent point $D$ is perpendicular to the direction of the normal vector $\vec{n}_{c}$ at point $D$. They can be expressed by vector equation as follows:

$$
v^{(12)} \cdot \overrightarrow{n_{c}}=0
$$

Supposed that the gear rack is fixed and the gear rolls on the gear rack, and the unit vectors of axes $x_{c}, y_{c}, z_{c}, x_{1}, y_{1}, z_{1}$, $\underline{x_{p}}, y_{p}$ and $z_{p}$ are expressed by $\overrightarrow{i_{c}}, \overrightarrow{j_{c}}, \overrightarrow{k_{c}}, \overrightarrow{i_{1}}, \overrightarrow{j_{1}}, \overrightarrow{k_{1}}, \overrightarrow{i_{p}}, \overrightarrow{j_{p}}$, $\overrightarrow{k_{p}}$ respectively. At this time, the direction of gear angular velocity vector is the negative direction of the $Z_{c}$ axis, and the relative motion velocity of the gear tooth surface and gear rack tooth surface at the meshing point can be expressed as follows:

$$
\overrightarrow{v^{(12)}}=\overrightarrow{\omega_{1}} \times \overrightarrow{M D}=\left|\begin{array}{ccc}
\overrightarrow{i_{c}} & \overrightarrow{j_{c}} & \overrightarrow{k_{c}} \\
0 & 0 & -\omega_{1} \\
x_{c} & y_{c}-r_{1} \varphi_{1} & z_{c}
\end{array}\right|=\omega_{1}\left(y_{c}-r_{1} \varphi_{1}\right) \overrightarrow{i_{c}}-x_{c} \omega_{1} \overrightarrow{j_{c}}
$$

where $\omega_{1}$ is angular velocity of gear in the coordinate system $S_{c}$, and $M D$ represents the distance from node $M$ to meshing point $D$.

The partial derivatives of Eq. (18) and Eq. (19) with respect to $k, t$ and $\theta$ may be solved respectively to obtain the normal vector of any point on the gear rack straight tooth surface and circular arc surface. The solution results are expressed as follows:

$$
\begin{gathered}
\overrightarrow{n_{c}^{1}}=\left[\begin{array}{c}
-\cos \alpha_{n} \sin \beta \sin \delta \mp \cos \delta \sin \alpha_{n} \\
\cos \beta \cos \alpha_{n} \\
-\sin \beta \cos \delta \cos \alpha_{n} \pm \sin \delta \sin \alpha_{n}
\end{array}\right] \\
\overrightarrow{n_{c}^{2}}=\left[\begin{array}{c}
r \sin \beta \sin \delta \sin \theta \mp r \cos \theta \cos \delta \\
-r \cos \beta \sin \theta \\
r \sin \beta \cos \delta \sin \theta \pm r \sin \delta \cos \theta
\end{array}\right]
\end{gathered}
$$

where, for the symbols of $\mp$ and \pm , the upper symbols 
should be used when the normal vectors corresponded to arc segment $B C$ and line segment $C D$ are calculated, and the lower symbols should be used when the normal vectors corresponded to line segment $E F$ and arc segment $F G$.

By substituting the relative velocity obtained by Eq. (24) and the normal vector obtained by Eq. (25) into Eq. (23), the meshing equation of involute tooth surface of the bevel gear can be expressed as follows:

$$
\begin{aligned}
\overrightarrow{v^{(12)} \cdot \overrightarrow{n_{c}^{1}}} & =\omega_{1}\left(y_{c}-r_{1} \varphi_{1}\right)\left(-\cos \alpha_{n} \sin \beta \sin \delta \mu \cos \delta \sin \alpha_{n}\right) \\
& -x_{c} \omega_{1} \cos \beta \cos \alpha_{n} \\
& =0
\end{aligned}
$$

Eq. (27) may be deduced by the expression of angle $\varphi_{1}$, and expressed as follows:

$$
\varphi_{1}=\frac{y_{c}}{r_{1}}-\frac{x_{c} \cos \beta \cos \alpha_{n}}{r_{1}\left(-\cos \alpha_{n} \sin \beta \sin \delta \mp \cos \delta \sin \alpha_{n}\right)}
$$

Similarly, by substituting the relative velocity obtained by Eq. (24) and the normal vector obtained by Eq. (26) into Eq. (23), the meshing equation of the transition surface of the bevel gear can be expressed as follows:

$$
\begin{aligned}
v^{(12)} \cdot \overrightarrow{n_{c}^{2}} & =\omega_{1}\left(y_{c}-r_{1} \varphi_{1}\right)(r \sin \beta \sin \delta \sin \theta \mu r \cos \theta \cos \delta) \\
& +x_{c} \omega_{1} r \cos \beta \sin \theta \\
& =0
\end{aligned}
$$

Eq. (29) may be deduced by the expression of angle $\varphi_{1}$, and expressed as follows:

$$
\varphi_{1}=\frac{y_{c}}{r_{1}}+\frac{x_{c} r \cos \beta \sin \theta}{r_{1}(r \sin \beta \sin \delta \sin \theta \mp r \cos \theta \cos \delta)}
$$

When the gear rotates at an angle of $\varphi_{1}$, a group of $k$ and $t$ and another group of $k$ and $\theta$ can be obtained by the meshing condition equation. So, Eq. (21) and Eq. (28) are the involute tooth surface equations of involute bevel gear, and Eq. (22) and Eq. (30) are the transition surface equations of the bevel gear.

\subsection{Solution of Tooth Surface Point Set of Bevel Gear Pair}

Based on the parameters described in section 2 and the mathematical models for tooth surface of bevel gear pair described in section 3.2, the flow chart of solution of tooth surface point set is shown in Figure 5.

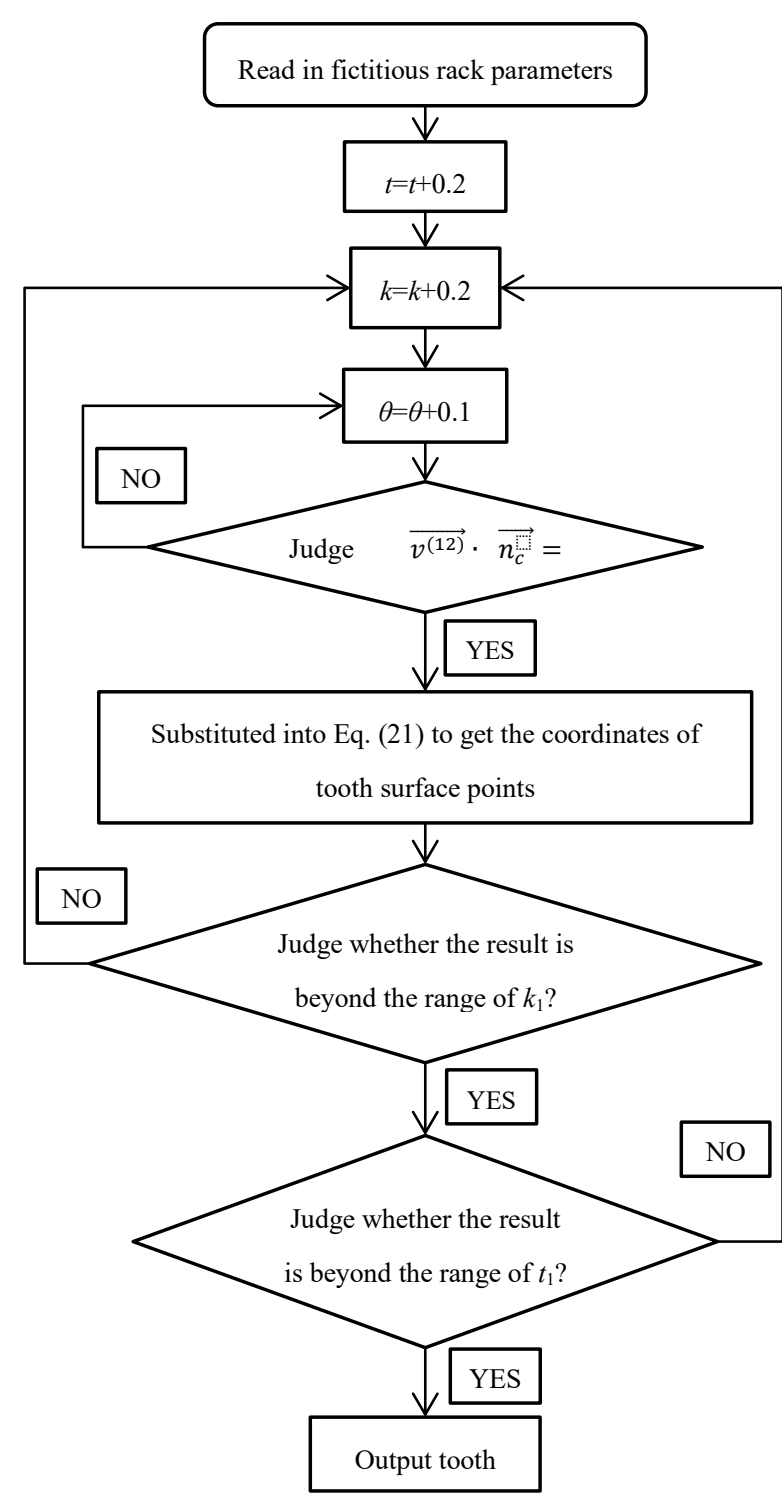

Fig. 5. Flow chart of solution of tooth surface point set

\section{Calculation and Design Example of Bevel Gear Pair in the Knotter}

\subsection{Introduction of the Bevel Gear Pair in the Knotter}

The bevel gear pair of driving the rope-gripping plate in the D-type knotter is a crossed axes bevel gear pair with shaft intersection angle of 98 degrees, as shown in Figure 6(a). In the knotter driven by double fluted discs, the bevel gear pair of driving the knotter jaw to rotate is an intersecting shaft bevel gear pair with shaft intersection angle of 98 degrees, as shown in Figure 6(b).

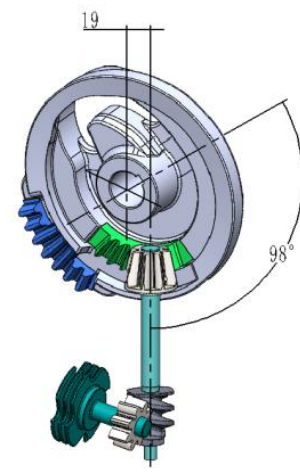

(a)

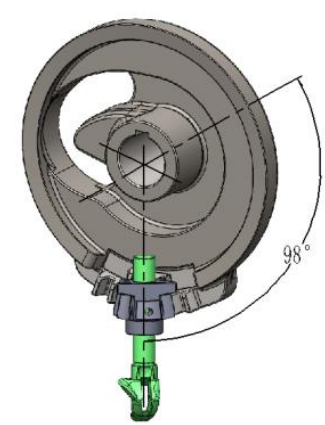

(b) 


\subsection{Calculation of Geometric Parameters of Bevel Gear Pair in the Knotter}

The known parameters of the bevel gear pair in two kinds of knotter are given in Table 1 and Table 2 respectively, and the solution process of their unknown parameters is shown in Figure 7. The solution results of the unknown parameters are shown in Table 3 and Table 4 respectively.

Table 1. The known parameters of bevel gear pair in D-type knotter

\begin{tabular}{ccccccccc}
\hline$m_{\mathrm{n}}$ & $\alpha_{\mathrm{n}}$ & $\beta_{1}$ & $\mathrm{Z}_{1}$ & $\mathrm{z}_{2}$ & $\delta_{1}$ & $\Sigma$ & $a$ & $l_{1}$ \\
\hline 4 & $20^{\circ}$ & 0 & 8 & 38 & $11.89^{\circ}$ & $98^{\circ}$ & $19 \mathrm{~mm}$ & $80 \mathrm{~mm}$ \\
\hline
\end{tabular}

Table 2. The known parameters of bevel gear pair in the knotter driven by double fluted discs

\begin{tabular}{ccccccccc}
\hline \multicolumn{8}{c}{ knotter driven by double fluted discs } \\
\hline$m_{\mathrm{n}}$ & $\alpha_{\mathrm{n}}$ & $\beta_{1}$ & $\mathrm{z}_{1}$ & $\mathrm{z}_{2}$ & $\delta_{1}$ & $\Sigma$ & $a$ & $l_{1}$ \\
\hline 4 & $20^{\circ}$ & 0 & 8 & 54 & $8.52^{\circ}$ & $98^{\circ}$ & 0 & $116 \mathrm{~mm}$ \\
\hline
\end{tabular}

Table 3. The solved parameters of bevel gear pair in D-type

\begin{tabular}{cccc}
\multicolumn{4}{c}{ knotter } \\
\hline parameter & results & parameter & results \\
\hline$\xi_{t 1}$ & 1.0001 & $\alpha_{t 1 L}$ & $19.6166^{\circ}$ \\
$r_{1}^{\prime}$ & $15.9984 \mathrm{~mm}$. & $\alpha_{t 1 R}$ & $19.6166^{\circ}$ \\
$\alpha_{t 1 R}^{\prime}$ & $19.5894^{\circ}$ & $\alpha_{t 1 L}^{\prime}$ & $19.5894^{\circ}$ \\
$\delta_{1}^{\prime}$ & $11.9064^{\circ}$ & $\alpha_{n}^{\prime}$ & $19.9848^{\circ}$ \\
$\beta_{1}^{\prime}$ & 0 & $m_{n}^{\prime}$ & 3.9996 \\
$\delta_{2}^{\prime}$ & $94.0225^{\circ}$ & $\beta_{2}^{\prime}$ & $14.2317^{\circ}$ \\
$\delta_{2}$ & $85.4223^{\circ}$ & $\beta_{2}$ & $12.4785^{\circ}$ \\
$r_{2}^{\prime}$ & $79.3721 \mathrm{~mm}$ & & \\
\hline
\end{tabular}

Table 4. The solved parameters of bevel gear pair in the knotter driven by double fluted dises

\begin{tabular}{cccc}
\hline parameter & results & parameter & results \\
\hline$\xi_{t 1}$ & 1.0013 & $\alpha_{t 1 L}$ & $19.7957^{\circ}$ \\
$r_{1}^{\prime}$ & $15.9792 \mathrm{~mm}$. & $\alpha_{t 1 R}$ & $19.7957^{\circ}$ \\
$\alpha_{t 1 R}^{\prime}$ & $19.5894^{\circ}$ & $\alpha_{t 1 L}^{\prime}$ & $19.5894^{\circ}$ \\
$\delta_{1}^{\prime}$ & $8.6058^{\circ}$ & $\alpha_{n}^{\prime}$ & $19.7957^{\circ}$ \\
$\beta_{1}^{\prime}$ & 0 & $m_{n}^{\prime}$ & 3.9948 \\
$\delta_{2}^{\prime}$ & $89.3929^{\circ}$ & $\beta_{2}^{\prime}$ & 0 \\
$\delta_{2}$ & $81.9480^{\circ}$ & $\beta_{2}$ & 0 \\
$r_{2}^{\prime}$ & $107.8596 \mathrm{~mm}$. & & \\
\hline
\end{tabular}

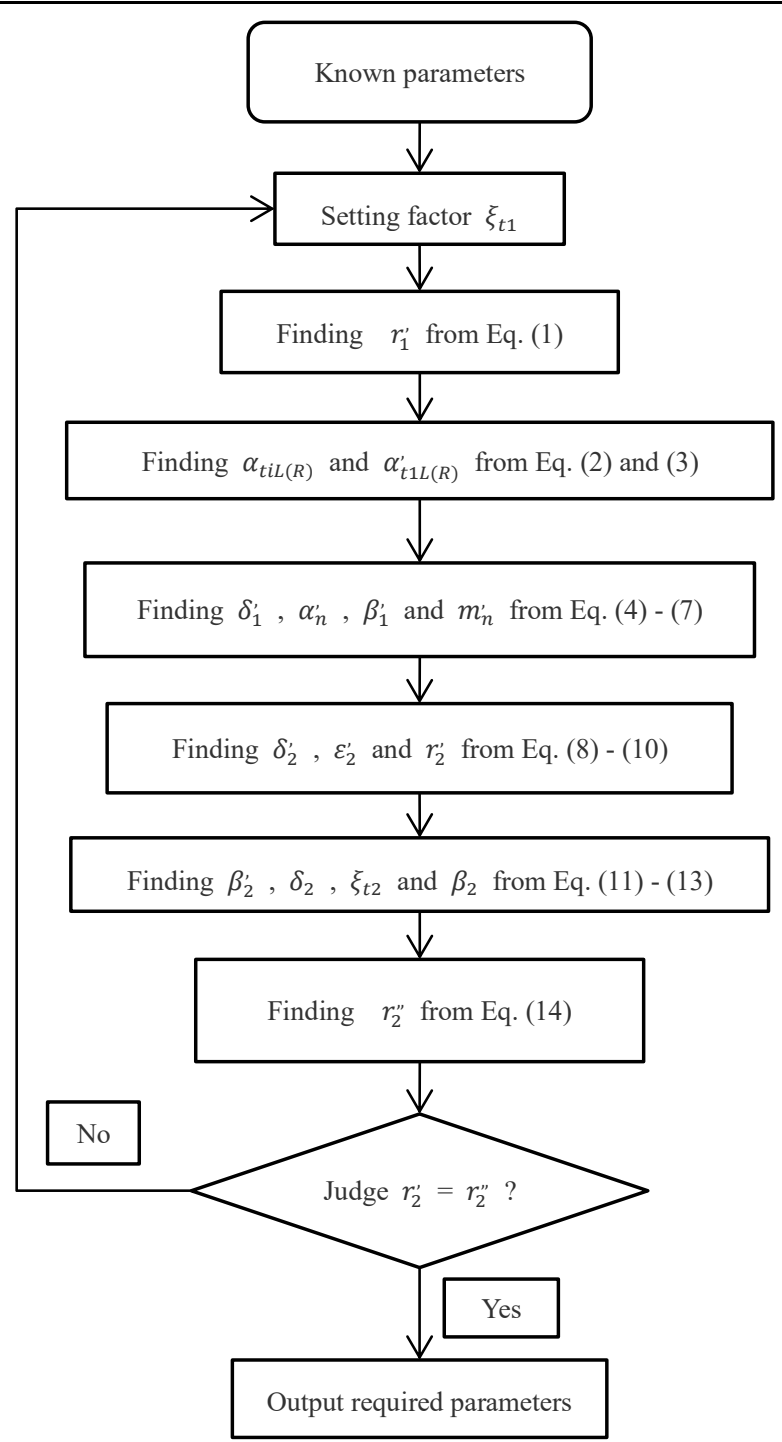

Figure 7. Flow chart of parameter solution of bevel gear pair

\subsection{Establishment of Accurate 3D Model of Bevel Gear Pair in the Knotter}

According to the flow chart shown in Figure 5, the tooth surface point sets of the bevel gear pair may be programmed to solve and visual display by using powerful calculation and graphic display function of MATLAB software [30, 31]. During the solution, the parameter $t$ is set to take value at 0.2 intervals within the range from 0 to 0.8 . The tooth width $k$ is set to take value at 0.2 intervals within the range from -10 to 0 . The parameters $\theta$ is set to take value at $0.1^{\circ}$ intervals within the range from $110^{\circ}$ to $180^{\circ}$. The point set obtained under MATLAB software is imported into Pro/Engineering software, and the accurate 3D model of bevel gear may be established according to the rule of "point - line - surface body". To the bevel gear pair in the knotter driven by double fluted discs, the process of its accurate modeling is shown in Figure 8. According to the motion requirements of the knotter, the bevel gear pair is designed as an incomplete bevel gear pair. 


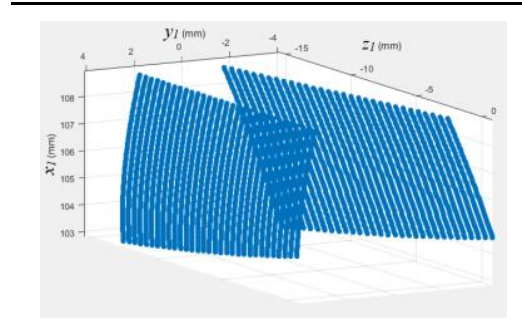

(a) The point set

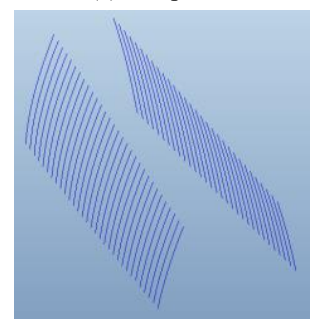

(c) Point connection

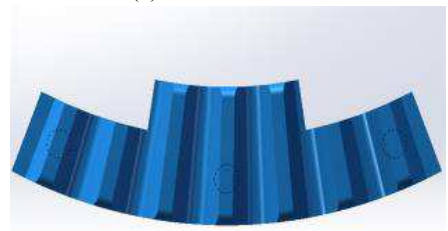

(e) 3D model

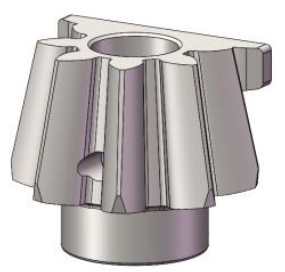

(g) 3D model

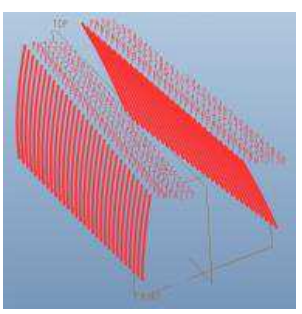

(b) Import into Pro/E

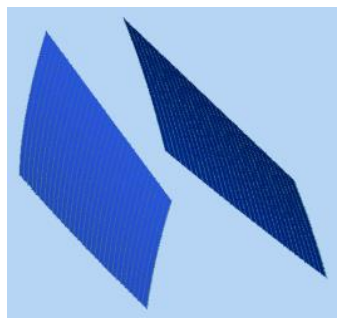

(d) Single tooth surface

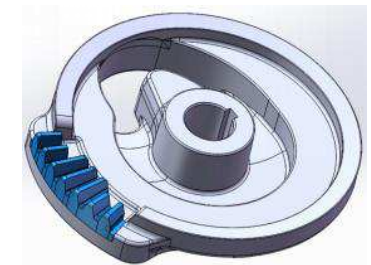

(f) Assembly model

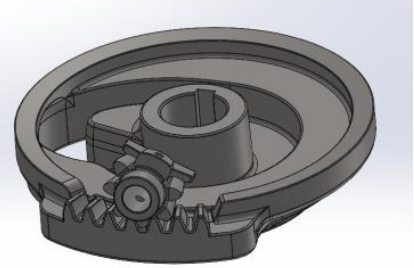

(h) Assembly model

Figure 8. 3D modeling process of the bevel gear pair in the knotter driven by double fluted discs

Similarly, the point set of tooth profile of the bevel gear pair in D-type knotter can be obtained, and their 3D assembly model is shown in Figure 9.

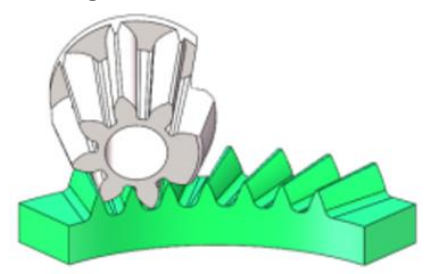

Figure 9. 3D assembly model of the bevel gear pair in the D-type knotter

\subsection{Meshing Transmission Simulation of Bevel Gear Pair} in the Knotter

4.4.1 Meshing transmission simulation of bevel gear pair with $98^{\circ}$ intersecting shaft in the knotter driven by double fluted discs

The 3D assembly model shown in Figure 10(a) is firstly import into ADAMS software, the material properties of parts are defined and the constraints among parts are added, as shown in Figure 10(b).

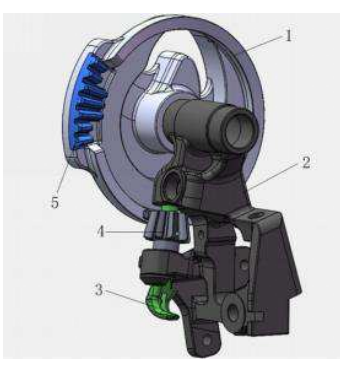

(a) Assembly model

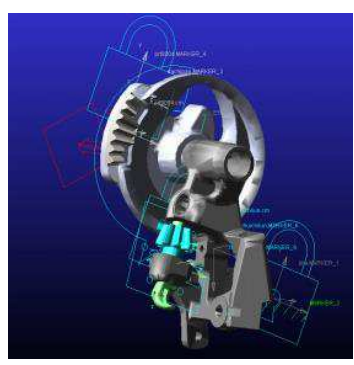

(b) Constraint model
Figure $103 \mathrm{D}$ assembly mode and ADAMS model 1.Large fluted disc; 2 . Knotter rack; 3. Knotter jaw; 4. Driven bevel gear; 5. Driving bevel gear

The rotary drive with $540^{\circ}$ percent second is added to the rotating pair of the driving bevel gear on the large fluted disc. The simulation time is set to 1 second, and the number of steps is 500. After finishing the simulation under ADAMS, the meshing process of single tooth of the bevel gear pair is shown in Figure 11.

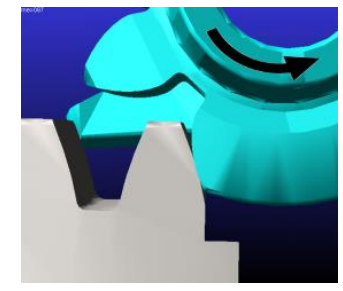

(a)Initial position

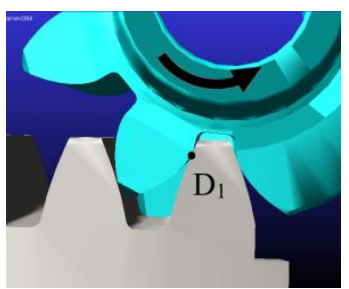

(c) Start meshing

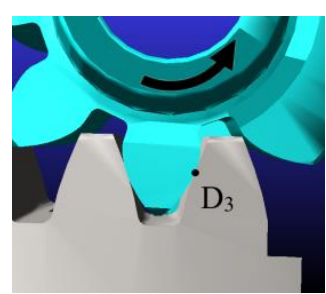

(e) Meshing half

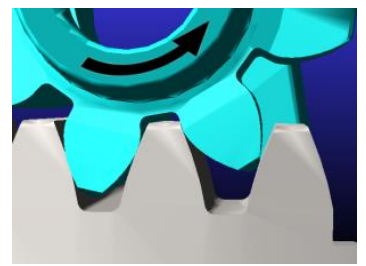

(g)Imminent separation

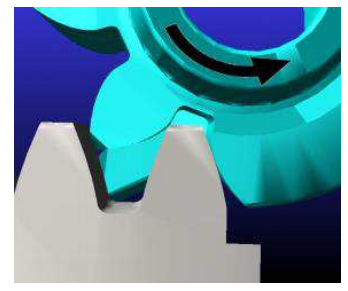

(b) Imminent meshing

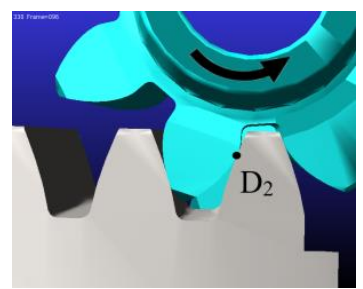

(d) Enter meshing

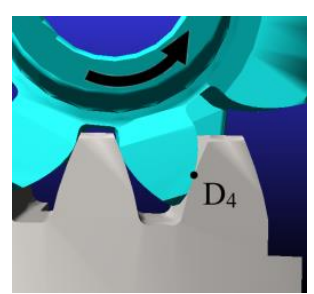

(f) Over half meshing

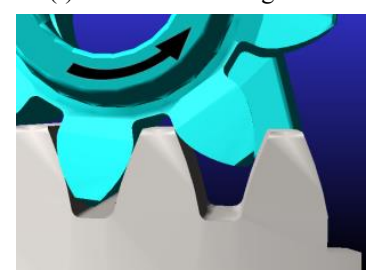

(h) Separation
Figure11 Meshing simulation of the bevel gear pair with $98^{\circ}$ intersecting shaft

It can be seen from the above simulation results that the meshing point moves smoothy from starting contact point to end contact point, which indicates that the calculation of the bevel gear pair based on the derived gear tooth surface equation is correct. The designed bevel gear pair may have stable meshing transmission, and complete the given 
transmission action.

4.4.2 Meshing transmission simulation of bevel gear pair with $98^{\circ}$ crossed shaft in D-type knotter

The same method as section 4.4.1 is used to simulate the transmission of the bevel gear pair with $98^{\circ}$ crossed shaft.

The 3D assembly model shown in Figure 12(a) is firstly import into ADAMS software, the material properties of parts are defined and the constraints among parts are added, as shown in Figure 12(b). After finishing the simulation under ADAMS, the meshing process of single tooth of the bevel gear pair is shown in Figure 13, and the simulation results are similar to the simulation in section 4.4.1.

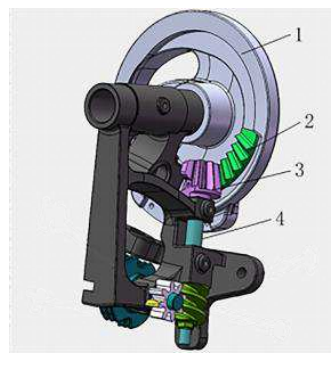

(a) Simplified Model

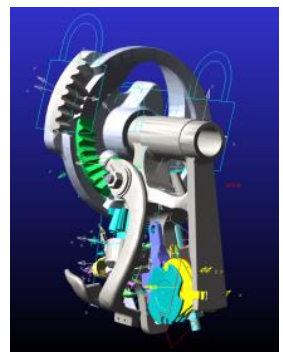

(b) Constraint model
Figure 12 3D assembly mode and ADAMS model 1. Compound gear disc; 2. Driving bevel gear; 3 . Driven bevel gear; 4.Worm shaft

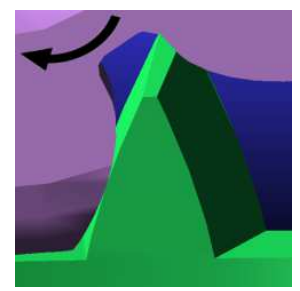

(a) Initial position

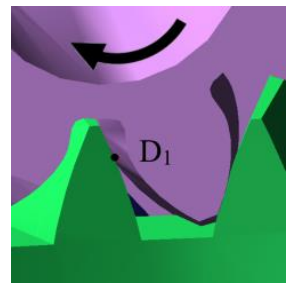

(c) Start meshing

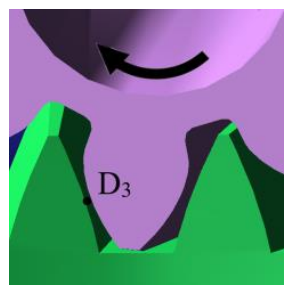

(e) Meshing half

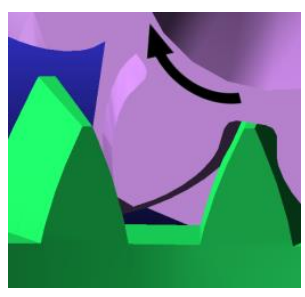

(g) Imminent separation

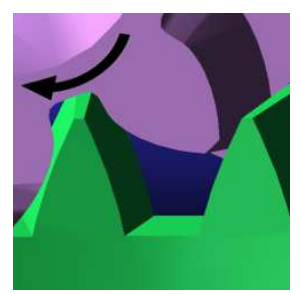

(b) Imminent meshing

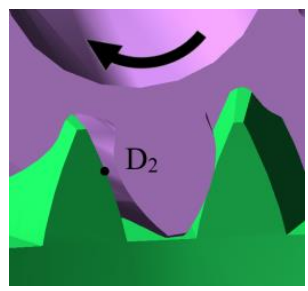

(d) Enter meshing

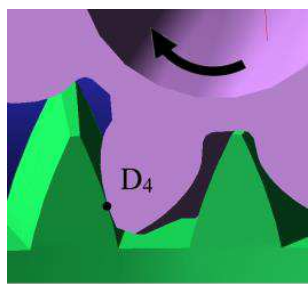

(f) Over half engagement

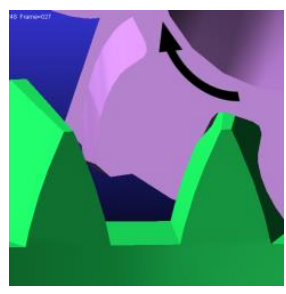

(h) Separation
Figure 13 Meshing simulation of the bevel gear pair with $98^{\circ}$ crossed shaft

4.5 Prototype Manufacturing and Transmission Test of Bevel Gear Pair in the Knotter

4.5.1 Prototype manufacturing and transmission test of bevel gear pair with 98 intersecting shaft in the knotter driven by double fluted discs

According to the accurate 3D model generated by section 4.3 , the prototype of bevel gear pair was manufactured by precision casting method. The actual prototypes are shown in Figure 14. The driving incomplete bevel gear and the large gear disc are integrally cast, and the driven incomplete bevel gear is individually cast.

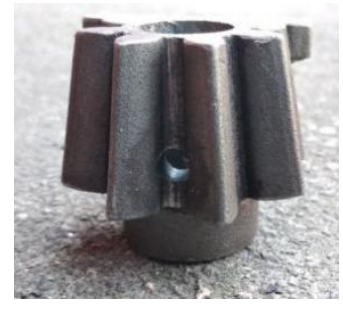

(a) Knotting driven bevel gear

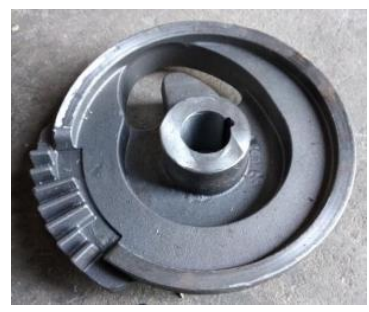

(b) Rope-gripping driving bevel gear
Figure14 Actual prototype of bevel gear pair with $98^{\circ}$ intersecting shaft

To carry out the transmission test, the above two bevel gears are assembled with other parts of the knotter. During the transmission test, the large gear disc is firstly driven to rotate, the driven incomplete bevel gear will mesh with the incomplete bevel gear on the large gear disc, and the knotting jaw coaxially fixed with the driven incomplete bevel gear realizes the trope-winding action. The process is shown in Figure 15 by taking a set of photos. The prototype motion of the bevel gear pair is very consistent with the simulation results under ADAMS, and can meet the motion requirements of the knotter.

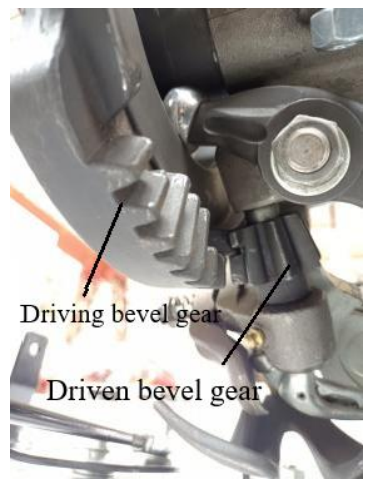

(a) Start meshing

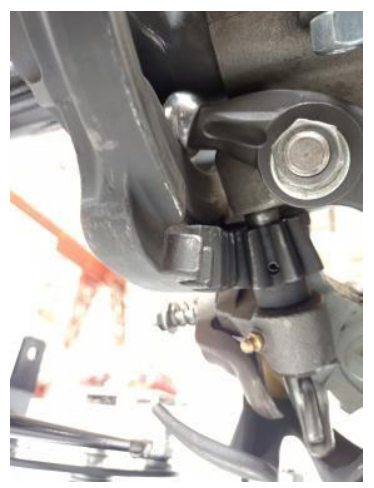

(c) Meshing process 2

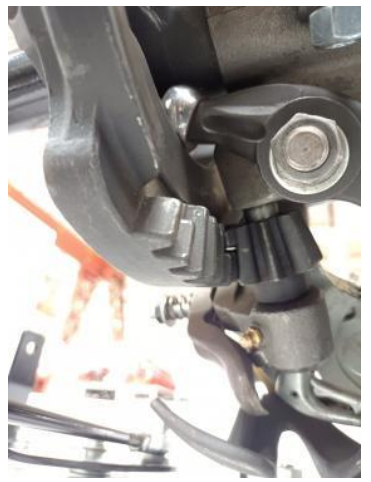

(b) Meshing process 1

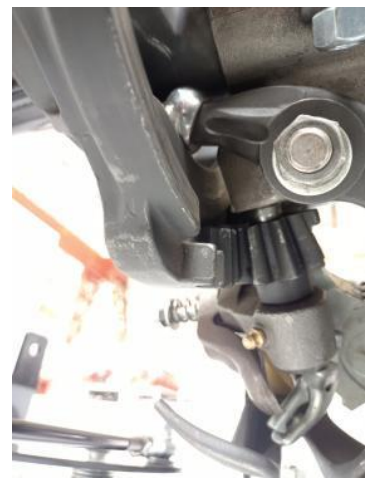

(d) Meshing process 3 


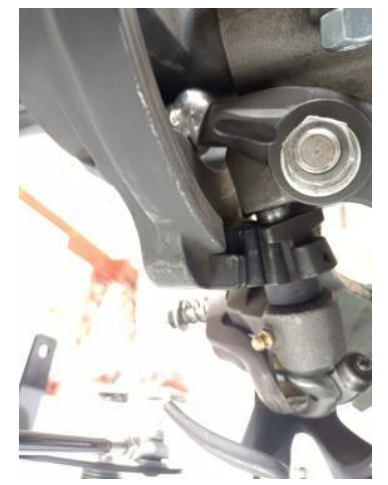

(e)Meshing process 4

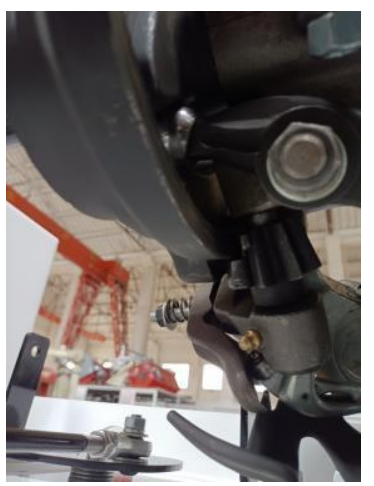

(g) Meshing process 6

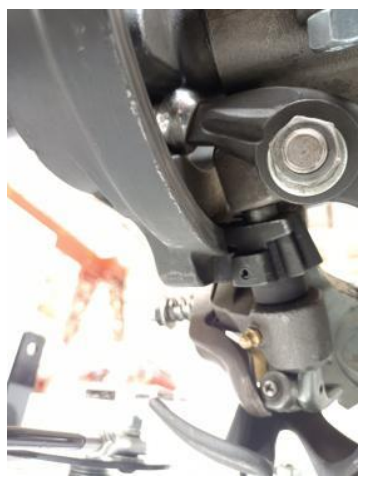

(f) Meshing process 5

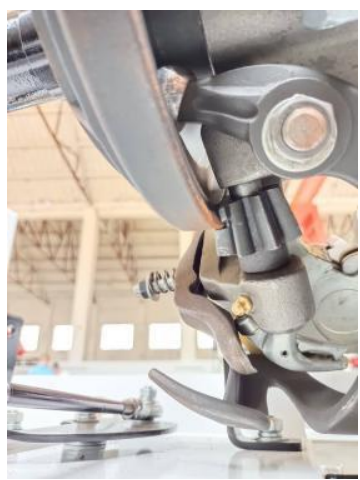

(h) End of meshing

Figure 15 Transmission process of bevel gear pair with $98^{\circ}$ intersecting shaft

\subsubsection{Prototype manufacturing and transmission test of bevel}

gear pair with $98^{\circ}$ Crossed shaft in D-type knotter

As mentioned in section 4.5.1, the actual prototypes are shown in Figure 16. The two bevel gears are assembled with other parts of the D-type knotter. The transmission process is shown in Figure 17 by taking another set of photos. The prototype motion of the bevel gear pair is also very consistent with the simulation results under ADAMS, and can meet the motion requirements of the D-type knotter.
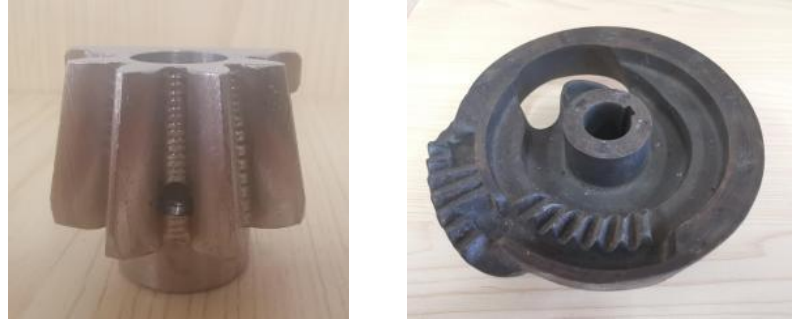

(a) Rope-gripping driven bevel gear

(b) Rope-gripping driving bevel gear

Figure 16 Actual prototype of bevel gear pair with $98^{\circ}$ crossed shaft

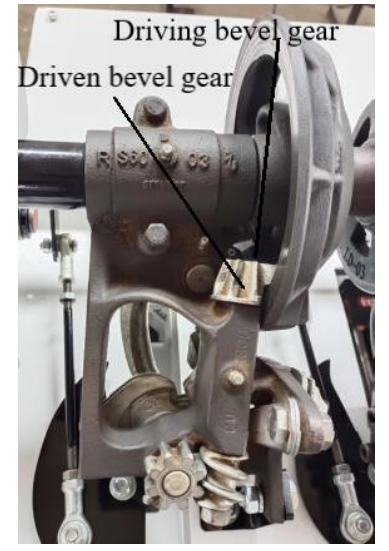

(a) Start meshing

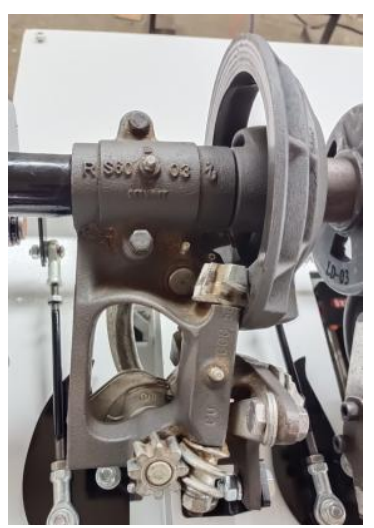

(c) Meshing process 2

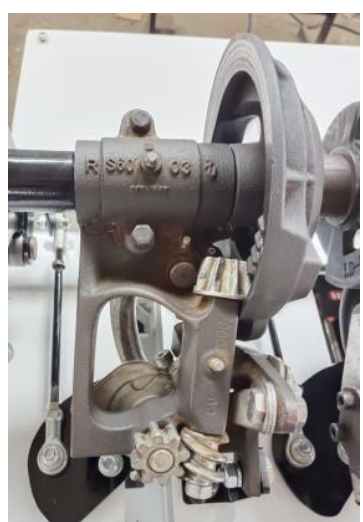

(e)Meshing process 4

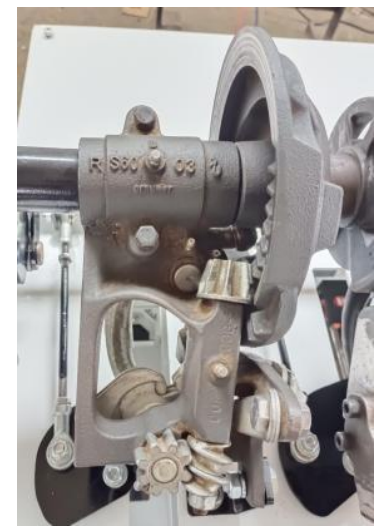

(g) Meshing process 6

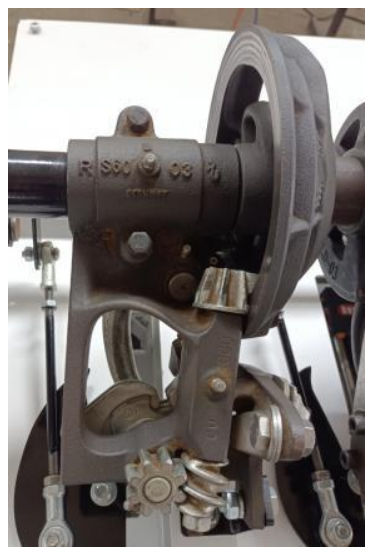

(b) Meshing process 1

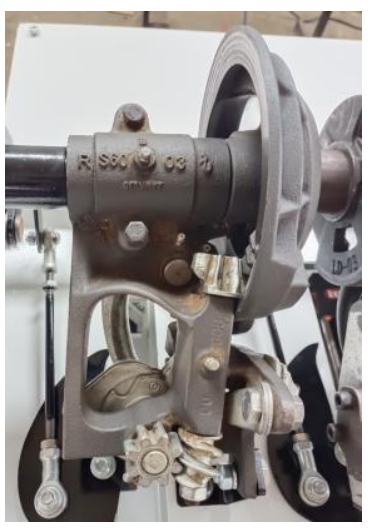

(d) Meshing process 3

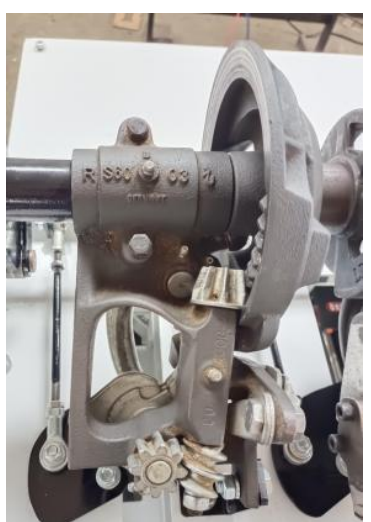

(f) Meshing process 5

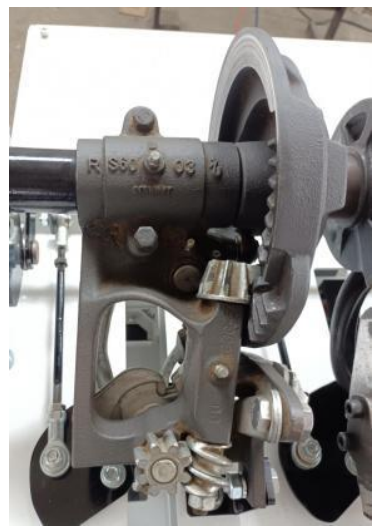

(h) End of meshing

Figure 17 Transmission process of bevel gear pair with $98^{\circ}$ crossed shaft

It can be seen from the above two transmission tests that the tooth profile of the bevel gear pair generated by the tooth surface meshing equation in section 3 may guarantee the 
correctness of bevel gear design and the accuracy of bevel gear transmission. The gear contour generation method based on the rule of "point - line - surface - body" is feasible and reliable.

\section{Conclusion}

(1) On the basis of analyzing the equations for solving the parameters of bevel gear pair with arbitrary crossed axes, the meshing equations of the bevel gears are derived, based on the installation parameter method and the meshing principle of bevel gears, which can provide a calculation model for the design of the tooth profile of space bevel gear.

(2) Taking the bevel gear pair in the knotter as design examples, the geometric parameters of the bevel gear pair of the knotter are solved, and the accurate $3 \mathrm{D}$ models of the bevel gear pair are established. Through the meshing transmission simulation of the bevel gear pair and the transmission test of the knotter, the results show that the designed bevel gear pair is accurate and stable, which proves the correctness of the mathematical model of bevel gear tooth surface.

\section{Authors' Contributions}

JY was in charge of the whole study and manuscript check; HW, RG and ZJ wrote the manuscript and participated in the experiment analysis. All authors read and approved the final manuscript.

\section{Authors' Information}

Jianjun Yin, born in 1973, is currently a professor at School of Agricultural Engineering, Jiangsu University, China. His research interests include advanced agricultural equipment and technology.

E-mail: yinjianjun@ujs.edu.cn

Han Wu, born in 1996, is a Master candidate at School of Agricultural Engineering, Jiangsu University, China.

E-mail: 2221916033@stmail.ujs.edu.cn

Zheng Ji, born in 1991, received his Master degree from School of Agricultural Engineering, Jiangsu University, China, in 2018.

E-mail: 973369227@qq.com

Maile Zhou, born in 1989, is currently an associate professor at School of Agricultural Engineering, Jiangsu University, China.

E-mail: 421247000@qq.com

Ruipeng Guo, born in 1996, is a Master candidate at School of Agricultural Engineering, Jiangsu University, China.

E-mail: 2211916026@stmail.ujs.edu.cn

\section{Acknowledgements}

Not applicable

\section{Availability of data and materials}

The datasets supporting the conclusions of this article are included within the article.

\section{Funding}

Supported by the National Key Research and Development Program of China (Grant No. 2016YFD0701701), National
Natural Science Foundation of China (Grant No. 52005221), the Natural Science Foundation of Jiangsu Province (Grant No. BK20200897), and the China Postdoctoral Science Foundation (Grant No. 2021M691315).

\section{Competing Interests}

The authors declare no competing financial interests.

\section{Author Details}

School of Agricultural Engineering, Jiangsu University, Zhenjiang 212013, China.

\section{References}

[1] S H Liu. Research on the Tooth Surface Construction and Meshing Analysis of Cross-Axis Bevel Gear Based on Spatial Conjugate Curves. Chongqing: Chongqing University of Technology, 2020. (in Chinese)

[2] F Y Zheng. Theory and Application of Moving-axis Gearing. Wuhan: Wuhan University of Technology, 2017. (in Chinese)

[3] F Guo, S C Wu, J X Liu, et al. Fatigue life assessment of bogie frames in high-speed railway vehicles considering gear meshing. International Journal of Fatigue, 2020, 132 (Mar.): 105353.1105353.12 .

[4] J H Wang, J W Yang, Q Li, et al. Remaining Useful Life Prediction for Degradation Process of Gear System with Contact Damage Model. International Journal of Performability Engineering, 2019, 15(1).

[5] P Ivkovi, M Ognjanovic, I Camagic, et al. Assessment of Probability of Gear Tooth Side Wear of a Planetary Gearbox. Tehnicki Vjesnik, 2020, 27(2):506-512..

[6] Z Y Wang, Z J Xing, H D Wang, et al. Research Status of Test Method for Bending Fatigue Life of Heavy Duty Gear. Materials Review, 2018. (in Chinese)

[7] D Ghribi, C Peyrac, M Octrue. Shot peening of gear tooth flanks: Search for an optimal surface topography against the micropitting. 2017.

[8] J Yan, X Chen, J Chen. Research on Monitoring Method of Gear Wear Status Based on Characteristics of Abrasive Particles. IOP Conference Series: Earth and Environmental Science, 2019, 252 (2): 022082 (8pp).

[9] Y Chen, L B Zang, J U Dong-Ying, et al. Research Status and Development Trend on Strengthening Technology of High Strength Automobile Gear Surface. China Surface Engineering, 2017. (in Chinese)

[10] S Mo, T Zhang, G Jin, et al. Elastohydrodynamic Lubrication Characteristics of Spiral Bevel Gear Subjected to Shot Peening Treatment. Mathematical Problems in Engineering, 2018, 2018(pt.7):3043712.1-3043712.12.

[11] M Du, L Yang. A basis for the computer-aided design of the topological structure of planetary gear trains-ScienceDirect. Mechanism and Machine Theory, 145.

[12] Y Sun, J Hu, G Li, et al. Gear reducer optimal design based on computer multimedia simulation. Journal of Supercomputing, 2018.

[13] MM Kane. Design Automation of Cylindrical Gear Manufacturing Processes, 2020.

[14] S Y Wang, C Meesap. Investigation on Mesh and Sideband Vibrations of Helical Planetary Ring Gear Using Structure, Excitation and Deformation Symmetries. Chinese Journal of Mechanical Engineering, 2018, 31(006):104.

[15] $\mathrm{H} \mathrm{Ge}, \mathrm{C}$ Wang. Research on the influence mechanism of friction factor of gear based on mathematical statistics principle. IOP Conference Series Materials Science and Engineering, 2019, 542: 012044.

[16] C Lin, Z Cai. Research on the method to calculate deformation of curve-face gear. ARCHIVE Proceedings of the Institution of Mechanical Engineers Part C Journal of Mechanical Engineering Science 1989-1996 (vols 203-210), 2017:095440621772172.

[17] H Ren, A Yin, W Song, et al. Vibration Monitoring With Dependencies Attention for Gear Hobbing Quality Evaluation. IEEE Sensors 
Journal, 2020, PP(99): 1-1.

[18] D S Ramteke, A Parey, R B Pachori. Automated gear fault detection of micron level wear in bevel gears using variational mode decomposition. Journal of Mechanical Science and Technology, 2019, 33(12).

[19] M Rababah, M Wasif, S A Iqbal. Parametric relationship between hypoid gear teeth and accurate face-milling cutter. Advances in Manufacturing, 2020, 8(4): 537-555.

[20] Gunbara, Hiroshi, Houjoh, et al. Method for remanufacturing largesized skew bevel gears using $\mathrm{CNC}$ machining center. Mechanism and Machine Theory: Dynamics of Machine Systems Gears and Power Trandmissions Robots and Manipulator Systems Computer-Aided Design Methods, 2015.

[21] G Figliolini, H Stachel, J Angeles. The Role of the Orthogonal Helicoid in the Generation of the Tooth Flanks of Involute-Gear Pairs With Skew Axes. Journal of Mechanisms \& Robotics, 2015, 7(1): 011003.

[22] Y C Tsai, W K Jehng. A kinematics parametric method to generate new tooth profiles of gear sets with skew axes. Mechanism \& Machine Theory, 1999, 34(6): 857-876.

[23] A Fuentes, J L Iserte, I Gonzalez-Perez, et al. Computerized design of advanced straight and skew bevel gears produced by precision forging. Computer Methods in Applied Mechanics and Engineering, 2011, 200(29-32): 2363-2377.

[24] T Schöler, H Binz, M Bachmann. Method for the pre-dimensioning of beveloid gears. Forschung im Ingenieurwesen, 2017.

[25] G Figliolini. On the synthesis of spatial cycloidal gears. Meccanica, 2013, 48(5): 1239-1249.

[26] J He, X Wu. Mobbing Tooth Flank Generating Theory andParameters Calculation of Conical Involute Gears. Xi 'an: Journal of $X i^{\prime}$ an Jiaotong University, 2003(09): 906-909. (in Chinese)

[27] L An, L Zhang, S Qin, et al. Mathematical design and computerized analysis of spiral bevel gears based on geometric elements. Mechanism and Machine Theory, 2021, 156: 104131.

[28] B C Wang, L T Zhang, P Xin, et al. Parametric Modeling and Contact Analysis of Skew Spiral Bevel Gears. IOP Conference Series Materials Science and Engineering, 2018, 439.

[29] H Ding, R Zhan, X Ad Ayi. Formational principle and accurate fitting methodology for a new tooth surface of the spiral bevel gear. International Journal of Simulation \& Process Modelling, 2016.

[30] E Faluvegi, C Z Mate, L Cristea. Mathematical Model of the Bevel Gears Flanks Considering the Cutting Machine Type. 2013.

[31] G Liu, H Fan. Pinion Tooth Surface Generation Strategy of Spiral Bevel Gears. Chinese Journal of Mechanical Engineering, 2012, 25(4): 753-759. 